\title{
Zika virus disease for neurologists
}

\author{
Daniel E. Smith, MD; J. David Beckham, MD; Kenneth L. Tyler, MD; Daniel M. Pastula, MD, MHS
}

\begin{abstract}
Purpose of review: Zika virus (ZIKV) was not initially thought to be an important cause of neurologic disease, but with the recent epidemic in the Western Hemisphere, there is a growing body of evidence for possible neurologic complications. This review discusses these in addition to what is known about modes of transmission, testing for the virus, as well as future directions. Recent findings: ZIKV disease has been associated with microcephaly and congenital eye disease in infants, as well as with Guillain-Barré syndrome, uveitis, myelitis, and meningoencephalitis in adults. Summary: Even though most infections are asymptomatic, there are important possible neurologic complications of ZIKV disease in both children and adults of which neurologists should be aware. Neurol Clin Pract 2016;6:515-522
\end{abstract}
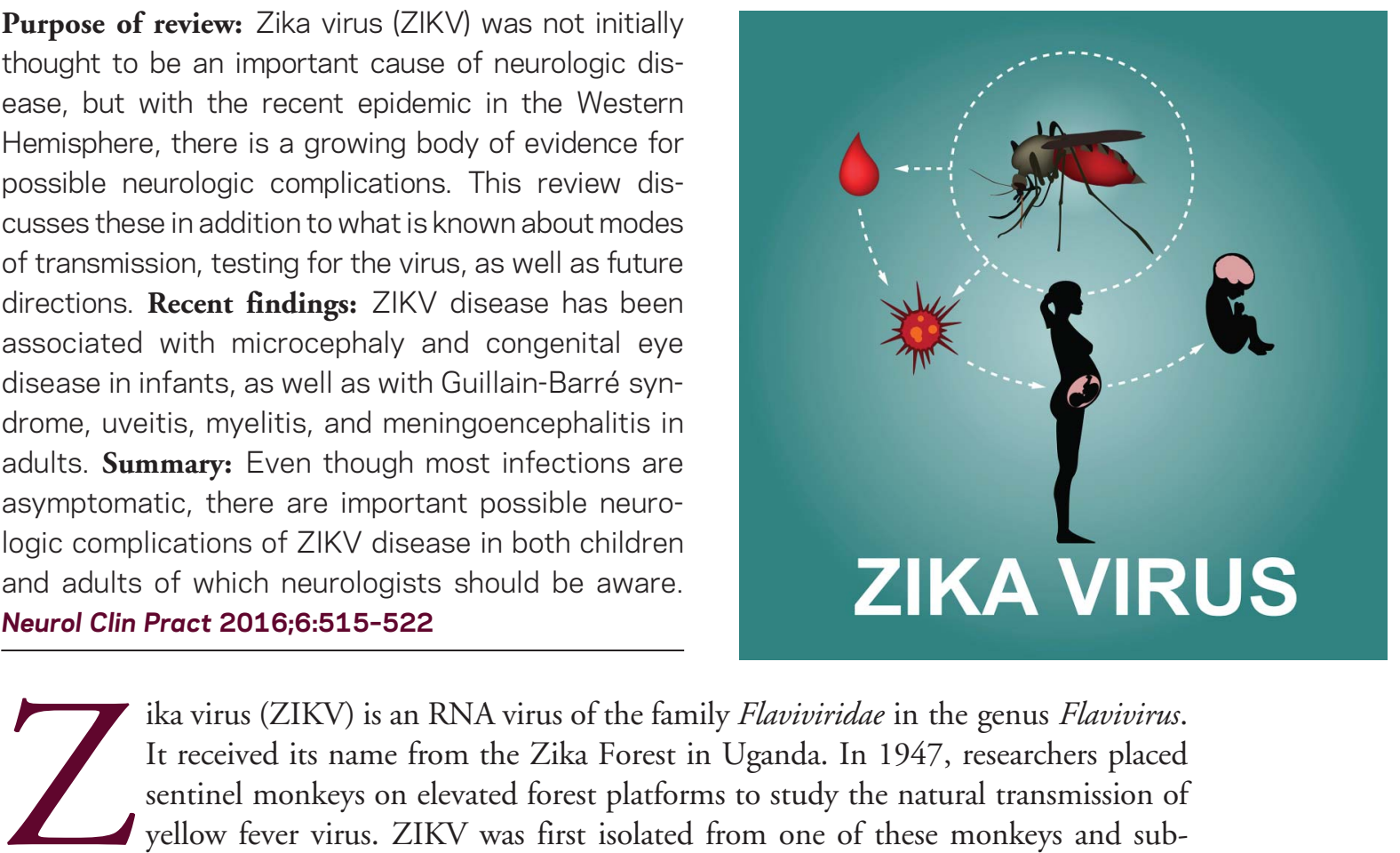

ika virus (ZIKV) is an RNA virus of the family Flaviviridae in the genus Flavivirus. It received its name from the Zika Forest in Uganda. In 1947, researchers placed sentinel monkeys on elevated forest platforms to study the natural transmission of yellow fever virus. ZIKV was first isolated from one of these monkeys and subsequently from a pool of Zika Forest-dwelling Aedes africanus mosquitoes. ${ }^{1,2}$

ZIKV was first studied in animals, and was shown to be neurotropic after serial brain passage in mice. ${ }^{3}$ Interestingly, injection of ZIKV into other animals, including cotton rats, guinea pigs, and rabbits, did not cause disease. ${ }^{3}$ Monkeys were shown to develop asymptomatic infection after subcutaneous inoculation with the mouse brain-passaged virus, but even after intracerebral inoculation, only 1 of 5 monkeys developed fever, and none more extensive illness. $^{3}$

There was early suggestion that ZIKV could infect humans as serosurveys in Africa showed that $6 \%$ of 99 sera samples were positive for ZIKV-specific neutralizing antibodies. ${ }^{3}$ However, ZIKV was not considered to be an important cause of human disease, as only 14 cases of symptomatic human ZIKV infection were documented between 1947 and 2006. ${ }^{4-8}$

The first documented human outbreak of ZIKV disease took place in Yap State in the Federated State of Micronesia in 2007.9 There were 49 confirmed, 59 probable, and 72 suspected cases of ZIKV disease. Through a seroprevalence survey, it was estimated that $73 \%$ of Yap residents aged 3 years or older had likely been infected. ${ }^{9}$ No deaths or serious complications were reported.

Neuro-Infectious Diseases Group, Department of Neurology and Division of Infectious Diseases, University of Colorado, Denver, Aurora.

Funding information and disclosures are provided at the end of the article. Full disclosure form information provided by the authors is available with the full text of this article at Neurology.org/cp.

Correspondence to: Daniel.Pastula@ucdenver.edu 


\section{It is likely that ZIKV can be transmitted through blood transfusion, although the frequency of}

\section{this remains unknown.}

The current ZIKV epidemic in South America likely began in late 2014 or early 2015. Local transmission of ZIKV disease was first reported in Brazil in May 2015. ${ }^{10}$ Evidence suggests local transmission in northeastern Brazil was occurring as early as March 2015. ${ }^{11,12}$ As of September 29, 2016, the virus had spread to 49 counties or territories throughout the Western Hemisphere, with just over 650,000 suspected or confirmed ZIKV disease cases reported to public health authorities. ${ }^{13}$

The US Centers for Disease Control and Prevention (CDC) activated their Emergency Operations Center on January 22, 2016, and the WHO declared a Public Health Emergency of International Concern on February 1, 2016. ${ }^{14}$ Locally acquired mosquito transmission of ZIKV disease has been reported in the United States territories of American Samoa, US Virgin Islands, and Puerto Rico, and in Miami-Dade County in Florida as of September 2016. ${ }^{15}$ There have also been over 3,565 travel-imported cases of ZIKV disease in the mainland United States reported as of this time. ${ }^{15-18}$

\section{Transmission and systemic symptoms}

ZIKV is predominantly transmitted through the bite of a mosquito, usually either Aedes aegypti or Aedes albopictus. These mosquitoes lay eggs near areas of standing water including buckets, bowls, pots, flower vases, and tires. They are active biters both during the day and night. These mosquitoes are also known carriers of both chikungunya and dengue viruses. ${ }^{19}$

ZIKV can also be transmitted through sexual intercourse. ${ }^{19}$ The first reported case of sexual transmission involved a virologist who had been working in Senegal, and upon returning home had vaginal intercourse with his wife, who developed symptomatic ZIKV infection without any other known exposure. ${ }^{20}$ There have also been reports of ZIKV transmission between a man and his nontraveling male partner, likely via anal sex, ${ }^{21}$ apparent transmission from a man to his female partner through oral sex, ${ }^{22}$ and recently of suspected female to male transmission. ${ }^{23}$

ZIKV has been detected in human semen. During the 2013 epidemic in French Polynesia, a man from Tahiti was being evaluated for hematospermia 2 weeks after a febrile illness compatible with ZIKV disease. ZIKV nucleic acid was detected by reverse transcription PCR (RT-PCR) in his semen and urine, but not blood. ${ }^{24}$ In another case, a 32-year-old man developed symptoms of ZIKV disease 2 days after returning home from South America. Two weeks after his recovery, blood, urine, and semen were collected, and RNA analysis showed a viral load roughly 100,000 times greater in the semen than in the blood or urine. ${ }^{25}$ It is not known how long ZIKV itself persists in semen, though ZIKV nucleic acid has been detected in semen as long as 62 days after symptomatic illness. ${ }^{26}$

It is likely that ZIKV can be transmitted through blood transfusion, although the frequency of this remains unknown. During the 2013 outbreak in French Polynesia, 3\% of the blood donor pool of asymptomatic donors was positive for ZIKV disease using nucleic acid testing. ${ }^{27}$ In addition, in Brazil, there was a report of probable ZIKV transmission through a platelet transfusion from a donor who became symptomatic several days after blood donation. ${ }^{28}$ There are no reported cases of blood transfusion transmission in the United States. The CDC examined blood donations in Puerto Rico between April 3 and June 11, 2016, using a nucleic acid test and found that $68 / 12,777(0.5 \%)$ samples were positive for ZIKV. ${ }^{29}$

Other flaviviruses such as dengue and West Nile viruses can be detected in breast milk, ${ }^{30-32}$ and while there is evidence for the presence of ZIKV in breast milk, there is no clear evidence for transmission. During the 2013 outbreak in French Polynesia, 2 women gave birth to 


\section{Aside from the association with the peripheral} nervous system, there are numerous case
reports of ZIKV affecting the CNS as well.

infants and both had symptoms of a viral disease 2 days prepartum and 3 days postpartum, respectively. RT-PCR detected ZIKV RNA in the serum of both newborns and in the breast milk of both mothers. Live virus was not cultured in breast milk. ${ }^{33}$ The CDC currently recommends mothers breastfeed their children given that there have been no proven cases to date of this mode of transmission, and the benefit likely outweighs risk. ${ }^{19}$

The majority of human infections (as high as $80 \%$ ) with ZIKV are likely asymptomatic. ${ }^{9}$ Those with symptoms typically develop a diffuse maculopapular rash, fever, arthralgias, myalgias, headache, or a nonpurulent conjunctivitis. ${ }^{9}$ The conjunctivitis is unusual as this rarely occurs following infection with other flaviviruses. The incubation period of ZIKV infection is unknown, but likely is between several days to 2 weeks. Viremia typically lasts for up to 1 week. Symptoms of the illness typically last several days to 1 week, and most people recover completely. ${ }^{34}$

\section{Neurologic symptoms and complications}

ZIKV disease is not unique in its ability to cause neurologic symptoms. Other flaviviruses known to cause neurologic disease in humans include West Nile, yellow fever, St. Louis encephalitis, dengue, and Japanese encephalitis viruses.

Based on a dramatic increase in cases of microcephalic infants during the recent Brazilian outbreak of ZIKV, there was speculation that ZIKV infection may be a potential etiology. This association has become clearer over time, and the CDC and WHO both recently announced that accumulating evidence supported a causal association. ${ }^{35}$

As an example, in February 2016, it was reported that a 25-year-old woman who had lived and worked in Natal since 2013 became pregnant in February 2015 and became ill during her 13 th week of gestation with a febrile illness. She was not initially tested for ZIKV, but an ultrasound at 32 weeks gestation suggested intrauterine growth restriction and demonstrated intracranial calcifications and hydrocephalus. Following termination of the pregnancy, autopsy of the fetal brain confirmed the ultrasound findings, but in addition showed a lack of gyri and poorly developed basal ganglia. ZIKV was detected via RT-PCR, and virions were found in the endoplasmic reticulum of cells on electron microscopy of brain tissue..$^{36,37}$

ZIKV RNA has also been detected in the amniotic fluid of 2 women who gave birth to children with microcephaly. In these cases, the women presented with antecedent symptoms consistent with ZIKV infection at 10 and 18 weeks of their pregnancies, respectively. The genome of the virus was sequenced in 1 child and found to share $97 \%-100 \%$ of its genome with isolates from the 2013 outbreak in French Polynesia. ${ }^{38}$

Recent work has shown that ZIKV is able to infect human neuronal precursor cells derived from pluripotent stem cells as well as brain "organoids" grown in culture. In both cases, infection is associated with apoptotic cell death and cell-cycle dysregulation, providing a plausible mechanism for microcephaly and abnormal brain development. ${ }^{39}$ The CDC is tracking pregnancy outcomes in the United States and territories. ${ }^{40}$

In addition to microcephaly, ZIKV disease has also been associated with ocular abnormalities in both infants and adults. One study looked at ocular findings in infants with microcephaly from presumed ZIKV infection. In this study, 29 mothers who gave birth to infants with microcephaly were included, and 23 of them reported symptoms compatible with ZIKV disease during their pregnancies. Of the 58 eyes examined, there were abnormalities found in $29 \%$ and about one-third of examined children had ocular abnormalities. The most common pathologies included pigment mottling of the retina and chorioretinal atrophy (seen in 11/17 
examined eyes) followed by optic nerve abnormalities in 8 eyes, bilateral iris coloboma in 1 child, and lens subluxation in 1 eye. ${ }^{41}$ The study was limited as it only looked at presumed and not proven cases of ZIKV infection, it included a population from only 1 hospital, and other infections known to cause ocular disease, including West Nile virus and toxoplasmosis, were not excluded. Another study looked at ocular findings in 3 children with presumed cases of congenital ZIKV disease infection, and reported additional phenotypes of torpedo maculopathy, vascular changes, and hemorrhagic retinopathy. ${ }^{42}$ Interestingly, a recent article described an infant with congenital ZIKV infection with a chorioretinal scar but without microcephaly. ${ }^{43}$ Finally, in addition to the known feature of conjunctivitis mentioned previously, a case of ZIKV-associated uveitis in an adult has been described. ${ }^{44}$

There is accumulating evidence that ZIKV infection is associated with Guillain-Barré syndrome (GBS). Some of the best evidence for this association comes from a case control study during the 2013-2014 outbreak in French Polynesia. ${ }^{45}$ Cases of GBS were age-, sex-, and residence-matched with controls with a nonfebrile illness (group 1) and age-matched with controls who had acute ZIKV disease and no neurologic symptoms (group 2). Ninety-eight percent of cases had a positive ZIKV immunoglobulin (Ig) $M$ or IgG test by indirect immunofluorescent or microsphere immunoassays and 100\% of cases had ZIKV-specific neutralizing antibodies, compared to $36 \%$ (odds ratio 59.7) and $56 \%$ (odds ratio 34.1) of controls in group 1, respectively. The majority of GBS cases (93\%) had ZIKV IgM, and 88\% of them experienced a transient viral illness a median of 6 days before the onset of neurologic symptoms, suggestive of preceding ZIKV disease. Electrodiagnostic findings suggested a predominant acute motor axonal neuropathy variant of GBS, though not all cases had complete electrodiagnostic testing. There were no deaths, but $29 \%$ of patients required respiratory assistance. While certainly suggestive of a ZIKV-GBS epidemiologic link, this study was limited as it relied on the presence of ZIKV antibodies and not on the presence of virus itself.

Another recent case-control study looked at a group of patients in the Salvador region of Brazil who met the Brighton Collaboration criteria for GBS. Compared with controls, a higher proportion of patients with GBS reported preceding rash and conjunctivitis at a time of known local ZIKV transmission, again suggesting a possible association. ${ }^{46}$ However, the findings of this study were preliminary.

In addition, there are several individual case reports of GBS with ZIKV detected in both urine and CSF. A recent study reported 2 patients with demyelinating GBS who had ZIKV viruria by RT-PCR, 1 at 15 days after neurologic symptoms onset and the other up to day $21 .{ }^{47}$ Another case report has emerged of a 24-year-old patient who developed GBS and had evidence of ZIKV via RT-PCR from blood, urine, and CSF. ${ }^{48}$

Another interesting case report described a man from Haiti who developed facial diplegia and acral paresthesias and then and went on to develop symptoms of Miller Fisher syndrome. The CSF was remarkable for protein of $114 \mathrm{mg} / \mathrm{dL}$, and ZIKV infection was highly likely given positive serum and CSF IgM by ELISA and plaque reduction neutralization testing (PRNT) results. ${ }^{49}$

Aside from the association with the peripheral nervous system, there are numerous case reports of ZIKV affecting the CNS as well. A recent case report described an association between ZIKV and meningoencephalitis in an 81-year-old healthy man. ${ }^{50}$ Ten days prior to the onset of symptoms, he had been on a cruise in New Caledonia, Vanuatu, and in New Zealand. He had an MRI of the brain performed showing subcortical white matter hyperintensities on fluid-attenuated inversion recovery sequences, and CSF showed a polymorphonuclearpredominant leukocytosis of 41 cells $/ \mathrm{mm}^{3}$, and a positive ZIKV RT-PCR. ZIKV was also cultured from CSF. ${ }^{50}$ He ultimately was discharged from the intensive care unit after 17 days, and had returned to his baseline mental status by 38 days later, with some residual weakness of his left arm.

ZIKV has also been associated with one reported case of myelitis. The patient was a 15-yearold girl who was admitted to a hospital in Guadeloupe after she developed arm pain, headaches, 
and conjunctivitis followed by progressively worsening left hemiparesis, urinary retention, and a thoracic sensory level. MRI showed 2 longitudinally extensive myelitis lesions of 4 segments each in the cervical and thoracic spinal cord. RT-PCR was positive for ZIKV RNA from the blood, urine, and CSF. She was treated with a 5-day course of methylprednisolone, and although she remained weak 1 month after presentation, she was ultimately able to walk unaided. ${ }^{51}$

In addition, there has been a case report of encephalopathy and seizures associated with ZIKV disease in 2 patients from Martinique. The first was a previously healthy young adult who developed generalized seizures 6 hours following symptoms of fever, headache, and arthralgias and was found to have ZIKV by RT-PCR of the serum, urine, and CSF. The second patient was a 70-year-old who had transient aphasia and an abnormal EEG with left frontotemporal slow waves, and again ZIKV RNA from blood, urine, and CSF. ${ }^{52}$

\section{Testing and reporting Zika virus infection}

Clinicians should suspect ZIKV disease in those with new rash, fever, arthralgias, myalgias, headache, or nonpurulent conjunctivitis with recent travel to ZIKV-endemic areas. Diagnosis of ZIKV infection primarily relies on molecular RT-PCR amplification of ZIKV RNA from body fluids (e.g., blood, urine, or CSF) during the first week or 2 of symptoms. ${ }^{53}$ ZIKV RT-PCR testing of serum is highly specific and can be performed rapidly, but its sensitivity is limited because it may be negative after the first week of illness when viremia has abated. ${ }^{53}$ Recent studies have shown that ZIKV nucleic acid may be detected in urine for 2 weeks or more after infection. In one observational study, no patients had detectable RNA via RT-PCR in the serum beyond 5 days but $9 / 11$ urine specimens were positive. In this study of 66 people, 61 had positive urine testing, and 33 had positive serum. ${ }^{54}$ The CDC Trioplex RT-PCR assay is authorized by the US Food and Drug Administration for ZIKV testing of urine. As of August 2016, the CDC recommends ZIKV RT-PCR testing of blood samples if within 7 days of symptom onset and urine sample if within 14 days of symptom onset. ${ }^{53,55}$

Serologic testing for ZIKV IgM antibodies may also aid in diagnosis, but may be difficult to interpret given heterologous antibody cross-reactions among the flaviviruses (e.g., dengue virus). For instance, a positive ZIKV IgM test by ELISA may reflect a recent Zika, dengue, or another related flavivirus infection. Virus-specific neutralizing antibody tests (e.g., PRNTs) can be used to better specify the infecting flavivirus; however, this may not be possible in all cases of secondary flavivirus infection as limited cross-reaction may sometimes occur. ${ }^{56}$ Antibody testing may be particularly useful in ruling out ZIKV disease as negative flavivirus IgM test results after 7 days of symptoms effectively rules out recent ZIKV infection. ${ }^{56}$ All suspected or confirmed ZIKV infections should be reported to local or state health departments, which can facilitate diagnostic testing.

\section{Prevention, treatment, and future directions}

Prevention of ZIKV infection is aimed at avoiding mosquito bites. Wearing long-sleeved shirts and pants when feasible, using screens on windows or air conditioning when indoors, and using insect repellent when outdoors is recommended..$^{57}$

The CDC has specific suggestions regarding prevention of sexual transmission. ${ }^{58}$ It is suggested that if a man lives in or has traveled to a ZIKV-endemic area, he should use condoms when having sex for 2 months after leaving if he is asymptomatic and for 6 months if he has had symptoms suggestive of ZIKV infection.

Per CDC guidelines, women who are pregnant should avoid traveling to areas with active transmission of ZIKV.59 Women who are planning pregnancy should postpone conception for at least 2 months if they or their male partner have been in a Zika-endemic area, and for 6 months if the male partner was symptomatic. Pregnant women should ensure male partners who have recently been to a Zika-endemic area use condoms. ${ }^{60}$

There is currently no available vaccine or antiviral therapy against ZIKV infection, but the first phase I trial for a synthetic DNA plasmid vaccine that encodes premembrane, membrane, 


\section{Take-home points}

ZIKV infection is usually either asymptomatic or causes a self-limited disease involving fever, rash, headache, myalgia, or nonpurulent conjunctivitis.

- Rarely, ZIKV infection has been associated with microcephaly and other birth defects, acute neuropathy/Guillain-Barré syndrome, myelitis, meningoencephalitis, uveitis, and maculopathy.

ZIKV infection can be prevented by using mosquito repellent and wearing longsleeved shirts and pants in endemic areas and temporarily avoiding unprotected sex with those who recently traveled to endemic areas. and envelope proteins (GLS-5700; NCT02809443) will begin later this year. ${ }^{61}$ Another phase I trial for a different DNA vaccine is also planned (VRC-ZKADNA085-00-VP; NCT02840487). Vaccines specific for Japanese encephalitis or yellow fever viruses are not thought to offer cross-protection against ZIKV infection.

Treatment is symptomatic and includes ensuring adequate hydration, rest, and fever reduction. ${ }^{34}$ Aspirin and nonsteroidal anti-inflammatory drugs should be avoided until dengue virus infection is ruled out given the risk of dengue hemorrhagic fever. ${ }^{62}$

There are a number of remaining questions related to ZIKV disease to be answered, including the effects of the timing of ZIKV infection during pregnancy and the risks and types of fetal disease, as well as the duration of ZIKV shedding in body fluids and their role in virus transmission. The development of in vitro and animal models to study viral pathogenesis will be critical to providing a rational basis for antiviral therapy and understanding the nature of ZIKV-associated neurodevelopmental and neurologic disease.

\section{REFERENCES}

1. Dick GW, Kitchen SF, Haddow AJ. Zika virus: I: isolations and serological specificity. Trans R Soc Trop Med Hyg 1952;46:509-520.

2. Wikan N, Smith DR. Zika virus: history of a newly emerging arbovirus. Lancet Infect Dis 2016;16: e119-e126.

3. Dick GW. Zika virus: II: pathogenicity and physical properties. Trans R Soc Trop Med Hyg 1952;46: 521-534.

4. Simpson DI. Zika virus infection in man. Trans R Soc Trop Med Hyg 1964;58:335-338.

5. Moore DL, Causey OR, Carey DE, et al. Arthropod-borne viral infections of man in Nigeria, 1964-1970. Ann Trop Med Parasitol 1975;69:49-64.

6. Fagbami AH. Zika virus infections in Nigeria: virological and seroepidemiological investigations in Oyo State. J Hyg 1979;83:213-219.

7. Filipe AR, Martins CM, Rocha H. Laboratory infection with Zika virus after vaccination against yellow fever. Arch Gesamte Virusforsch 1973;43:315-319.

8. Olson JG, Ksiazek TG, Suhandiman, Triwibowo. Zika virus, a cause of fever in Central Java, Indonesia. Trans R Soc Trop Med Hyg 1981;75:389-393.

9. Duffy MR, Chen TH, Hancock WT, et al. Zika virus outbreak on Yap Island, Federated States of Micronesia. N Engl J Med 2009;360:2536-2543.

10. PAHO. Timeline of emergence of Zika virus in the Americas. Available at: paho.org/hq/index.php? option=com_content\&view=article\&id=11959\&Itemid=41711\&lang=en. Accessed July 14, 2016.

11. Campos GS, Bandeira AC, Sardi SI. Zika virus outbreak, Bahia, Brazil. Emerg Infect Dis 2015;21: $1885-1886$.

12. Zanluca C, Melo VC, Mosimann AL, Santos GI, Santos CN, Luz K. First report of autochthonous transmission of Zika virus in Brazil. Mem Inst Oswaldo Cruz 2015;110:569-572.

13. PAHO. Zika Cumulative Cases. Available at: http://www.paho.org/hq/index.php?option=com content\&view $=$ article\&id=12390\&Itemid=42090\&lang=en. Accessed October 6, 2016.

14. CDC. Zia virus: areas with Zika. Available at: cdc.gov/zika/geo/index.html. Accessed July 10, 2016.

15. Dirlikov E, Ryff KR, Torres-Aponte J, et al. Update: ongoing Zika virus transmission: Puerto Rico, November 1, 2015-April 14, 2016. MMWR Morb Mortal Wkly Rep 2016;65:451-455.

16. CDC. Case counts in the US. 2016. Available at: cdc.gov/zika/geo/united-states.html. Accessed August 23, 2016.

17. CDC. Advice for people living in or traveling to South Florida. 2016. Available at: cdc.gov/zika/ intheus/florida-update.html. Accessed August 23, 2016.

18. CDC. Zika virus disease in the United States, 2015-2016. Available at: cdc.gov/zika/geo/unitedstates.html. Accessed July 14, 2016.

19. CDC. Zika virus: transmission and risks. Available at: cdc.gov/zika/transmission/index.html. Accessed July 11, 2016. 
20. Foy BD, Kobylinski KC, Chilson Foy JL, et al. Probable non-vector-borne transmission of Zika virus, Colorado, USA. Emerg Infect Dis 2011;17:880-882.

21. Deckard DT, Chung WM, Brooks JT, et al. Male-to-male sexual transmission of Zika virus-Texas, January 2016. MMWR Morb Mortal Wkly Rep 2016;65:372-374.

22. D'Ortenzio E, Matheron S, Yazdanpanah Y, et al. Evidence of sexual transmission of Zika virus. N Engl J Med 2016;374:2195-2198.

23. Davidson ASS, Komoto K, Rakeman J, Weiss D. Suspected female-to-male sexual transmission of Zika virus-New York City, 2016. MMWR Morb Mortal Wkly Rep 2016;22:716-717.

24. Musso D, Roche C, Robin E, Nhan T, Teissier A, Cao-Lormeau VM. Potential sexual transmission of Zika virus. Emerg Infect Dis 2015;21:359-361.

25. Mansuy JM, Dutertre M, Mengelle C, et al. Zika virus: high infectious viral load in semen, a new sexually transmitted pathogen? Lancet Infect Dis 2016;16:405.

26. Atkinson B, Hearn P, Afrough B, et al. Detection of Zika virus in semen. Emerg Infect Dis 2016;22:940.

27. Musso D, Stramer SL, Busch MP; AABB Transfusion-Transmitted Diseases Committee; International Society of Blood Transfusion Working Party on Transfusion-Transmitted Infectious Diseases. Zika virus: a new challenge for blood transfusion. Lancet 2016;387:1993-1994.

28. Barjas-Castro ML, Angerami RN, Cunha MS, et al. Probable transfusion-transmitted Zika virus in Brazil. Transfusion 2016;56:1684-1688.

29. Kuehnert MJ, Basavaraju SV, Moseley RR, et al. Screening of blood donations for Zika virus infectionPuerto Rico, April 3-June 11, 2016. MMWR Morb Mortal Wkly Rep 2016;65:627-628.

30. Centers for Disease Control and Prevention (CDC). Possible West Nile virus transmission to an infant through breast-feeding: Michigan, 2002. MMWR Morb Mortal Wkly Rep 2002;51:877-878.

31. Hinckley AF, O'Leary DR, Hayes EB. Transmission of West Nile virus through human breast milk seems to be rare. Pediatrics 2007;119:e666-e671.

32. Barthel A, Gourinat AC, Cazorla C, Joubert C, Dupont-Rouzeyrol M, Descloux E. Breast milk as a possible route of vertical transmission of dengue virus? Clin Infect Dis 2013;57:415-417.

33. Besnard M, Lastere S, Teissier A, Cao-Lormeau V, Musso D. Evidence of perinatal transmission of Zika virus, French Polynesia, December 2013 and February 2014. Euro Surveill 2014;19.

34. CDC. Zika virus: symptoms, diagnosis, and treatment. Available at: cdc.gov/zika/symptoms/index. html. Accessed July 14, 2016.

35. Rasmussen SA, Jamieson DJ, Honein MA, Petersen LR. Zika virus and birth defects: reviewing the evidence for causality. N Engl J Med 2016;374:1981-1987.

36. Mlakar J, Korva M, Tul N, et al. Zika virus associated with microcephaly. N Engl J Med 2016;374: 951-958.

37. Martines RB, Bhatnagar J, Keating MK, et al. Notes from the field: evidence of Zika virus infection in brain and placental tissues from two congenitally infected newborns and two fetal losses: Brazil, 2015. MMWR Morb Mortal Wkly Rep 2016;65:159-160.

38. Calvet G, Aguiar RS, Melo AS, et al. Detection and sequencing of Zika virus from amniotic fluid of fetuses with microcephaly in Brazil: a case study. Lancet Infect Dis 2016;16:653-660.

39. Garcez PP, Loiola EC, Madeiro da Costa R, et al. Zika virus impairs growth in human neurospheres and brain organoids. Science 2016;352:816-818.

40. CDC. Outcomes of pregnancies with laboratory evidence of possible Zika virus infection in the United States, 2016. Available at: cdc.gov/zika/geo/pregnancy-outcomes.html. Accessed July 11, 2016.

41. de Paula Freitas B, de Oliveira Dias JR, Prazeres J, et al. Ocular findings in infants with microcephaly associated with presumed Zika virus congenital infection in Salvador, Brazil. JAMA Ophthalmol Epub 2016 Feb 9.

42. Miranda HA II, Costa MC, Frazao MA, Simao N, Franchischini S, Moshfeghi DM. Expanded spectrum of congenital ocular findings in microcephaly with presumed Zika infection. Ophthalmology 2016;123:1788-1794.

43. Ventura CV, Maia M, Dias N, Ventura LO, Belfort R Jr. Zika: neurological and ocular findings in infant without microcephaly. Lancet 2016;387:2502.

44. Furtado JM, Esposito DL, Klein TM, Teixeira-Pinto T, da Fonseca BA. Uveitis associated with Zika virus infection. N Engl J Med 2016;375:394-396.

45. Cao-Lormeau VM, Blake A, Mons S, et al. Guillain-Barre Syndrome outbreak associated with Zika virus infection in French Polynesia: a case-control study. Lancet 2016;387:1531-1539.

46. Styczynski AMJ, Krow-Lucal E, Percio J, et al. Guillain-Barré Syndrome Outbreak: Bahia State, Brazil, 2016; 65th EIS Conference. Atlanta, GA: CDC; 2016.

47. Roze B, Najioullah F, Ferge JL, et al. Zika virus detection in urine from patients with Guillain-Barre syndrome on Martinique, January 2016. Euro Surveill 2016;21.

48. Brasil P, Sequeira PC, Freitas AD, et al. Guillain-Barre syndrome associated with Zika virus infection. Lancet 2016;387:1482. 
49. Kassavetis P, Joseph JB, Francois R, Perloff MD, Berkowitz AL. Zika virus-associated Guillain-Barre syndrome variant in Haiti. Neurology 2016;87:336-337.

50. Carteaux G, Maquart M, Bedet A, et al. Zika virus associated with meningoencephalitis. N Engl J Med 2016;374:1595-1596.

51. Mecharles S, Herrmann C, Poullain P, et al. Acute myelitis due to Zika virus infection. Lancet 2016; 387:1481.

52. Roze B, Najioullah F, Signate A, et al. Zika virus detection in cerebrospinal fluid from two patients with encephalopathy, Martinique, February 2016. Euro Surveill 2016;21.

53. CDC. Zika virus: diagnostic testing. Available at: cdc.gov/zika/hc-providers/diagnostic.html. Accessed July 11, 2016.

54. Bingham AM, Cone M, Mock V, et al. Comparison of test results for Zika virus RNA in urine, serum, and saliva specimens from persons with travel-associated Zika virus disease: Florida, 2016. MMWR Morb Mortal Wkly Rep 2016;65:475-478.

55. Interim guidance for Zika virus testing of urine: United States, 2016. MMWR Morb Mortal Wkly Rep 2016;65:474.

56. Rabe IB, Staples JE, Villanueva J, et al. Interim guidance for interpretation of Zika virus antibody test results. MMWR Morb Mortal Wkly Rep 2016;65:543-546.

57. CDC. Zika virus: prevention. Available at: cdc.gov/zika/prevention/. Accessed July 11, 2016.

58. CDC. Zika virus: Zika and sexual transmission. Available at: cdc.gov/zika/transmission/sexual-transmission. html. Accessed July 14, 2016.

59. CDC. Guidelines for travelers visiting friends and family in areas with chikungunya, dengue, or Zika. Available at: nc.cdc.gov/travel/page/guidelines-vfr-chikungunya-dengue-zika. Accessed July 14, 2016.

60. CDC. Zika virus: women and their partners who are thinking about pregnancy. Available at: cdc.gov/ zika/pregnancy/thinking-about-pregnancy.html. Accessed July 15, 2016.

61. Eunjung Cha A. Scientists announce important Zika milestone: first vaccine ready for human trials. Washington Post; June 20, 2016.

62. CDC. Zika virus: clinical evaluation and disease. Available at: cdc.gov/zika/hc-providers/clinicalevaluation. html. Accessed July 4, 2016.

Received July 28, 2016. Accepted in final form September 15, 2016.

\section{AUTHOR CONTRIBUTIONS}

D.E. Smith: primary author for the manuscript. J.D. Beckham and K. Tyler: assisted with reviewing and editing the manuscript. D. Pastula: assisted with writing, reviewing, and editing the manuscript.

\section{STUDY FUNDING}

No targeted funding reported.

\section{DISCLOSURES}

D.E. Smith and J.D. Beckham report no disclosures. K.L. Tyler serves on DSMB for LPath and DNAtrix and on the scientific advisory board of PML Consortium; serves as an Associate Editor for Journal of Neurovirology and Neurology Today and on the editorial boards of Neurology ${ }^{\circledR}$, Annals of Neurology, Apoptosis, JAMA Neurology, Experimental Neurology, Journal of Infectious Disease, Microbial Pathogenesis, and Virology; receives publishing royalties for Handbook of Clinical Neurology, vol. 95 (Elsevier, 2010) and Harrison's Principles \& Practices of Internal Medicine, 19th ed. (McGraw-Hill, 2015); serves as a consultant for Hoffman La Roche; and receives research support from NIH and Department of Veterans Affairs. D.M. Pastula reports no disclosures. Full disclosure form information provided by the authors is available with the full text of this article at Neurology.org/cp.

\section{Related articles from AAN physician and patient resources}

Neurology Today ${ }^{\circledR} \quad$ Neurotodayonline.com

As the Zika Outbreak Reaches US Territories, a Case-Control Study Provides the Strongest Evidence Yet of a Link to Guillain-Barré Syndrome April 7, 2016;16:1,25-28. 


\section{Neurology ${ }^{\circ}$ Clinical Practice}

Zika virus disease for neurologists

Daniel E. Smith, J. David Beckham, Kenneth L. Tyler, et al.

Neurol Clin Pract 2016;6;515-522 Published Online before print October 13, 2016

DOI 10.1212/CPJ.0000000000000307

This information is current as of October 13, 2016

$\begin{array}{ll}\begin{array}{l}\text { Updated Information } \& \\ \text { Services }\end{array} & \begin{array}{l}\text { including high resolution figures, can be found at: } \\ \text { http://cp.neurology.org/content/6/6/515.full.html }\end{array} \\ \text { References } & \text { This article cites } 41 \text { articles, } 1 \text { of which you can access for free at: } \\ \text { http://cp.neurology.org/content/6/6/515.full.html\#\#ref-list-1 } & \text { This article, along with others on similar topics, appears in the } \\ \text { following collection(s): } \\ \text { Guillain-Barre syndrome } \\ \text { http://cp.neurology.org//cgi/collection/guillainbarre_syndrome } \\ \text { Viral infections } \\ \text { http://cp.neurology.org//cgi/collection/viral_infections } \\ \text { Information about reproducing this article in parts (figures,tables) or in } \\ \text { its entirety can be found online at: } \\ \text { http://cp.neurology.org/misc/about.xhtml\#permissions } \\ \text { Information about ordering reprints can be found online: } \\ \text { http://cp.neurology.org/misc/addir.xhtml\#reprintsus }\end{array}$

Neurol Clin Pract is an official journal of the American Academy of Neurology. Published continuously since 2011, it is now a bimonthly with 6 issues per year. Copyright $@ 2016$ American Academy of Neurology. All rights reserved. Print ISSN: 2163-0402. Online ISSN: 2163-0933.

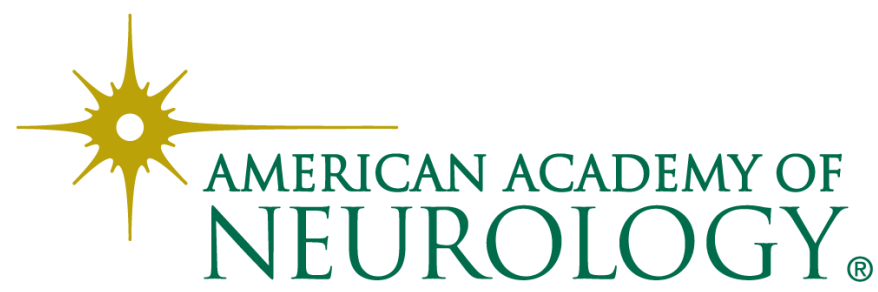

